\title{
Apuntes sobre Tiburcio de Aguirre y Antonio Milón, clientes del Escultor Luis Salvador Carmona, y sus encargos para Brozas y la iglesia del Rosario en el Real Sitio de San Ildefonso
}

\author{
Vicente Méndez Hernán \\ Universidad de Extremadura
}

RESUMEN:

El presente trabajo tiene como objetivo definir la personalidad de los clientes que acudieron al taller de Luis Salvador Carmona para encargarle las esculturas de Ntra. Sra. del Socoro, que hoy se venera en la parroquia de Brozas (Cáceres), y las del Pilar y San Francisco Javier que hizo para la iglesia del Rosario, en el Real Sitio de San Ildefonso (Segovia). El profesor Martín González y Eileen Lord las atribuyeron, respectivamente, a la gubia del artista, aunque sin las aportaciones documentales que ahora presentamos. El primer encargo partió de la iniciativa de Tiburcio de Aguirre y Ayanz, y de Antonio Milón López los dos restantes. Ambos estuvieron directamente relacionados con el entorno de la reina Isabel de Farnesio, de cuya inclinación hacia el arte y la cultura en general se dejó influir Tiburcio de Aguirre, y de su lado más piadoso Antonio Milón, su confesor personal.

\section{PALABRAS CLAVE:}

Luis Salvador Carmona, Tiburcio de Aguirre, Antonio Milón, Brozas, Real Sitio de San Ildefonso.

\section{ABSTRACT.}

This paper aims to define the persona of the clients who turned to the workshop of Luis Salvador Carmona to commission the sculpture of Our Lady of Perpetual Succour, which is today located at the Parish of Brozas (Cáceres), as well as the sculptures of Our Lady of the Pillar and of Saint Francis Xavier, which were done for the Holy Rosary Church located in Real Sitio de San Ildefonso (Segovia). Professor Martín González, as well as Eileen Lord, both considered them to be the work of the aforementioned artist; however, they did so without the documentary proof that we are presenting here. The first work was commissioned by Tiburcio de Aguirre Ayanz, while Antonio Milón López was responsible for the initiative which was required for the other two. Both were directly related with all that which surrounded Queen Elisabeth Farnese at the time, whose inclination towards art and culture in general helped to influence Tiburcio de Aguirre, while the more devout Antonio Milón was her personal confessor.

\section{KEYWORDS:}

Luis Salvador Carmona, Tiburcio de Aguirre, Antonio Milón, Brozas, Real Sitio de San Ildefonso.

Para la realización de este trabajo hemos contado con una ayuda de la Junta de Extremadura, canalizada a través del “Apoyo a los grupos de investigación catalogados", en el marco del equipo "Arte y Patrimonio Moderno y Contemporáneo" (HUM012). 


\section{INTRODUCCIÓN}

El estudio de la esfera personal del cliente siempre ha sido una labor tan sugerente como el hecho de indagar y profundizar en la personalidad del artista depositario de su confianza, y en la naturaleza del encargo que el promotor había concebido en función de sus deseos y expectativas personales; analizar el objetivo que suscitó el contrato, las circunstancias que envolvieron la determinación del cliente, o las relaciones que éste pudo llegar a establecer con el maestro a cuyo taller terminó acudiendo, son aspectos que nos han aportado, en muchas ocasiones, datos para precisar la cronología de una obra, conocer los pormenores del proceso de contratación, o justificar las influencias artísticas presentes en nuestro objeto de estudio. Toda una amplia serie de aspectos que aún cobra mayor importancia cuando lo desconocemos prácticamente todo sobre una obra en cuestión, salvo el hecho de su evidencia estilística para ser atribuida a un artista en concreto, o vinculada a una escuela en particular ${ }^{1}$.

Esa serie de apreciaciones adquieren aún mayor relevancia cuando se trata de un artista de la trascendencia de Luis Salvador Carmona (1708-1767), y de piezas tan señeras como la escultura de Ntra. Sra. del Socorro, que hoy se venera en la iglesia de la Asunción, en Brozas (Cáceres) (Fig. 1), y las de San Francisco Javier y la Virgen del Pilar que hizo para la parroquia de Nuestra Señora del Rosario, en el Real Sitio de San Ildefonso (Figs. 2 y 3). Se trata de tres obras atribuidas a la gubia del maestro natural de Nava del Rey, que la crítica histórico-artística ha aceptado de forma unánime dada la evidencia estilística que presentan las figuras². Sin embargo, el hallazgo de una parte de la documentación relacionada con la talla mariana del Socorro, y la localización de la carta de pago que el maestro otorgó en 1758 por las dos que hizo para el Real Sitio de San Ildefonso, publicada en 1953 y hasta ahora no relacionada

\footnotetext{
Sobre la clientela, cabe citar el ya clásico trabajo del profesor MARTÍN GONZÁLEZ, Juan J., El artista en la sociedad española del siglo XVII, Cátedra, Madrid, 1984, pp. 109 y ss.

2 Sobre la escultura del Socorro vid. MARTín GONZÁLEZ, Juan J., Luis Salvador Carmona. Escultor y académico, Alpuerto, Madrid, 1990, p. 269; las tallas para San Ildefonso las publicó LORD, Eileen A., "Luis Salvador Carmona en el Real Sitio de San Ildefonso (La Granja)", en Archivo Español de Arte, Volumen XXVI, n. ${ }^{\circ} 101$, Madrid, 1953, pp. 24-25 y 27.
}

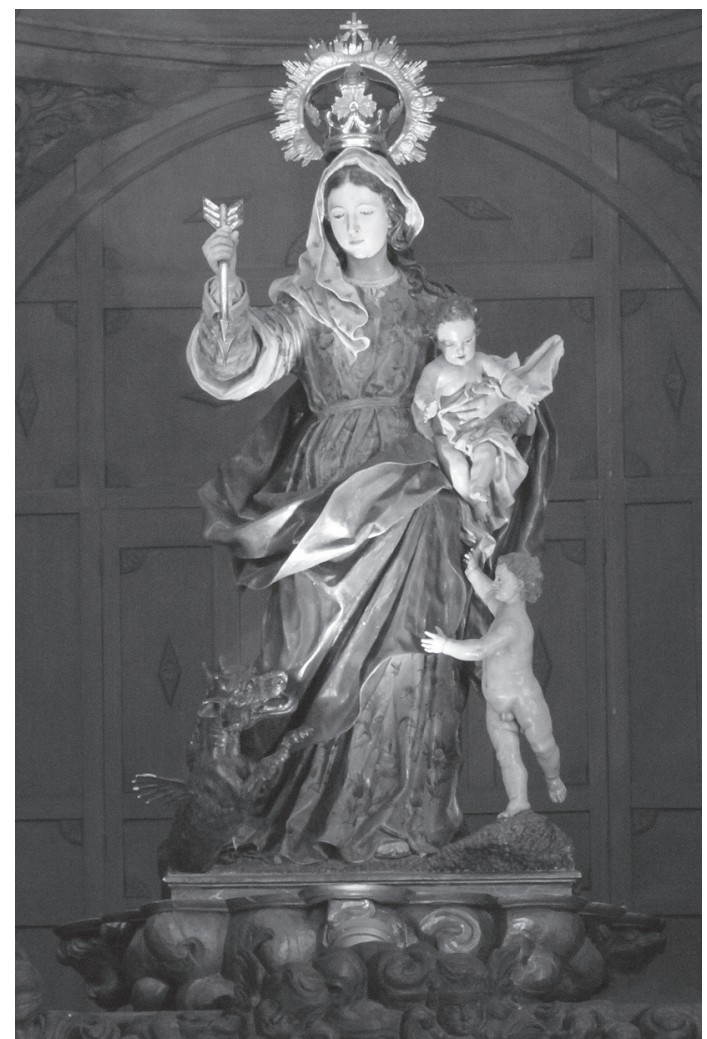

Fig. 1. Luis Salvador Carmona. Virgen del Socorro. Brozas (Cáceres), iglesia de Nuestra Señora de la Asunción, c.1751-1754. Foto del autor.

con las obras en cuestión ${ }^{3}$, nos han permitido profundizar en el entorno clientelar que rodeó a este artista vallisoletano, asentado en Madrid desde que entrara en el taller de Juan Alonso Villabrille y Ron (c.1663-1732) como aprendiz en $1723^{4}$, y matizar, además de ampliar, lo que hasta ahora conocíamos sobre las obras.

En el Memorial que elevó en 1748 solicitando la plaza de escultor de cámara ${ }^{5}$, Luis Salvador Carmona dejaba constancia no solo de su ingreso - dos años antes- en la nómina de escultores encargados de ejecutar el programa decorativo del Palacio Real Nuevo de Madrid, sino también del contacto que estrechó a partir de entonces con el entorno más cercano a la

GONZÁlEZ PALENCIA, Ángela, Colección de Documentos sobre Madrid, Instituto de Estudios Madrileños, Madrid, 1953, pp. 573-575.

4 SALORT PONS, Salvador, "Juan Alonso de Villabrille y Ron, maestro de Luis Salvador Carmona”, en Archivo Español de Arte, Volumen LXX, n. ${ }^{\circ}$ 280, Madrid, 1997, p. 457.

5 MORENO VILLA, J., "Memorial del escultor D. Luis Salvador Carmona", en Archivo Español de Arte y Arqueología, n. ${ }^{\circ} 22$, Madrid, 1932, p. 98. 


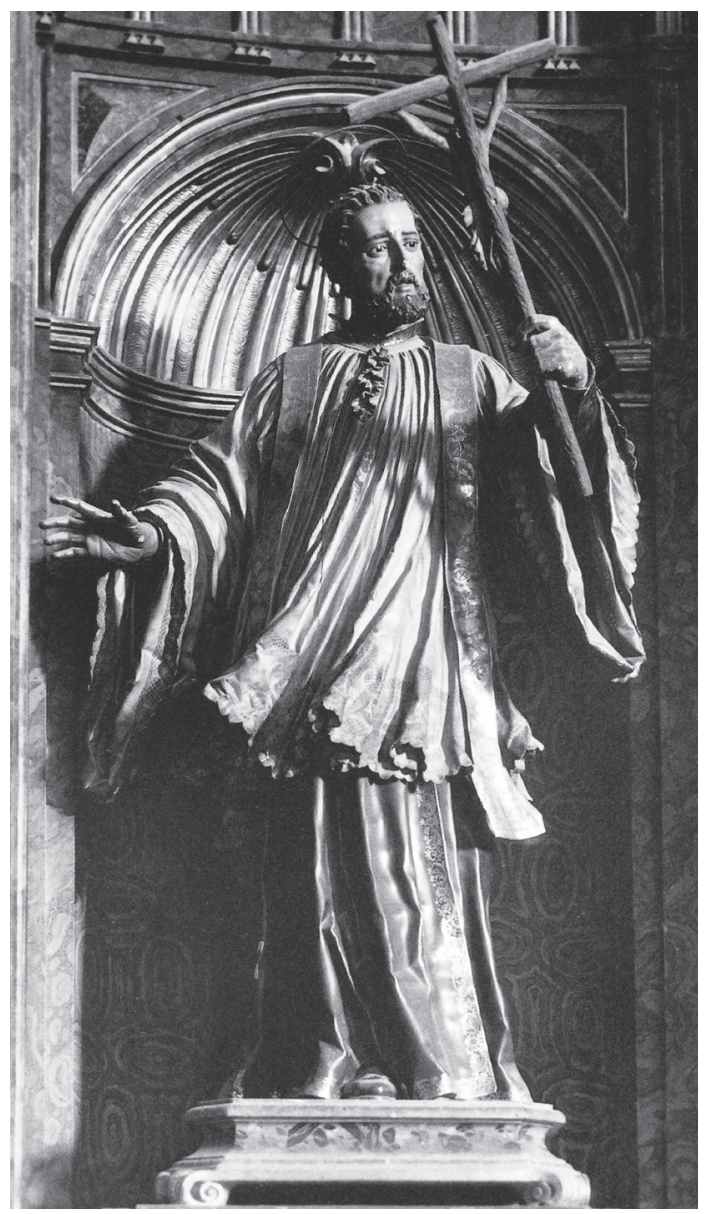

Fig. 2. Luis Salvador Carmona. San Francisco Javier. Real Sitio de San Ildefonso (Segovia), iglesia de Nuestra Señora del Rosario, c. 1751-1752. Fotografía M. ${ }^{a}$ Concepción García Gaínza, El escultor Luis Salvador Carmona, Burlada, 1990, fig.50.

familia real, al cual estaban vinculados Tiburcio de Aguirre y Antonio Milón López, clientes, respectivamente, de la talla brocense y de las obras de San Ildefonso. Si a todo ello sumamos la admiración que causó en la corte el Cristo del Perdón, que Luis Salvador tenía acabado en 1751 en respuesta a un encargo personal de la reina Isabel de Farnesio (1692-1766) destinado a la iglesia del Rosario de aquel mismo Real Sitio $^{6}$, tendremos un factor lo suficientemente sugerente como para relacionarlo -a tenor de los factores que analizamos- con la decisión que tomaron Aguirre y Antonio Milón de acudir al taller de Carmona al objeto de encargarle las obras citadas.

El escultor tenía acabada la efigie en febrero de 1751: LORD, Eileen A., Luis Salvador..., opus cit., p. 15.

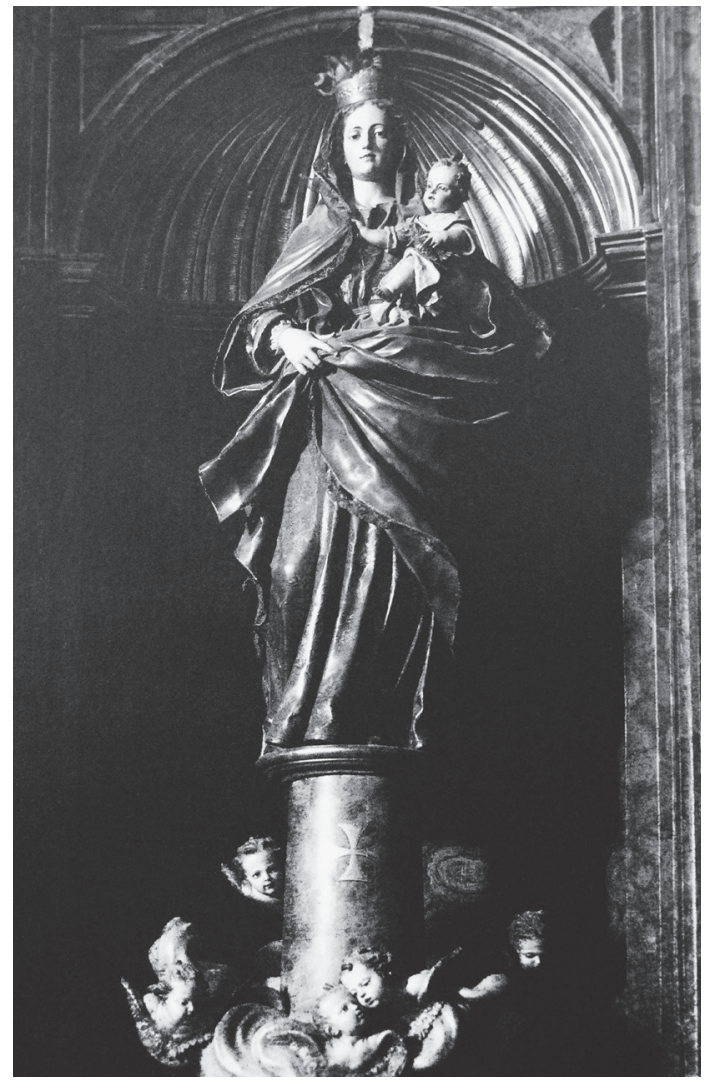

Fig. 3. Luis Salvador Carmona. Virgen del Pilar. Real Sitio de San Ildefonso (Segovia), iglesia de Nuestra Señora del Rosario, c. 1751-1752. Fotografía M. ${ }^{a}$ Concepción García Gaínza, El escultor Luis Salvador Carmona, Burlada, 1990, fig.27.

La escultura de Nuestra Señora del Socorro y la personalidad de Tiburcio de Aguirre

La talla mariana fue dada a conocer en 1990 por el profesor Martín González (1923-2009), quien la adscribió al catálogo del escultor ante la evidencia estilística que presenta la obra, de singular belleza y extraordinaria calidad técnica, y propuso para su datación el año $1750^{7}$. Si a esta referencia sumamos la documentación procedente del Real Convento de San Pedro, que existió en Brozas bajo los designios de las monjas comendadoras del hábito y caballería de la Orden militar de Alcántara, podremos reconstruir parcialmente la trayectoria histórico-artística de la obra. Aunque la documentación conservada no es prolija en datos, hay uno en particular que nos permite vincular la escultura mariana del Socorro con el citado monasterio, y afirmar sin reservas que originalmente

\footnotetext{
MARTÍN GONZÁLEZ, Juan J., Luis Salvador Carmona..., opus cit., p. 269.
} 
fue encargada para formar parte de las tallas que se veneraban en su iglesia; se trata de una escritura fechada en Madrid el 23 de septiembre de 1807, mediante la cual el presbítero brocense don Joaquín Vicente Salgado solicitaba indulgencias al nuncio apostólico para quien venerase la efigie de la Virgen del Socorro que existía en el templo del convento alcantarino ${ }^{8}$. Si a este dato unimos el nombre de quien ejercía el patronazgo sobre las monjas comendadoras a mediados del siglo XVIII, podremos concretar sin ninguna dificultad la relación que tuvo con el escultor Luis Salvador Carmona, y justificar así el encargo de la obra y su presencia en la villa de Brozas, y analizar también la trayectoria personal del patrono para explicar las razones que le llevaron a convertirse en uno de los clientes del afamado taller madrileño; una trayectoria, por otra parte, que hasta ahora no se había abordado de un modo global, aunando los distintos aspectos y matices de lo que sin duda fue una vida plena de interés por las distintas esferas de la vida pública y privada en las que participó.

En virtud de la carta que fray Antonio Calderón y Robles, capellán del monasterio de San Pedro, remitió al patrono del mismo con fecha de 9 de octubre de 1749 al objeto de informarle sobre el estado en el que se encontraba el edificio, sabemos que dicho patronato lo ejercía, por designio real, una de las personalidades más importantes e influyentes de la España ilustrada, don Felipe Tiburcio de Aguirre y Ayanz de Arbizu Salcedo y Lodosa (Vitoria, 1707-Madrid, $1^{1767)^{9}}$, a la sazón consiliario (1752) y viceprotector (1753) de la Real Academia de Bellas Artes de San Fernando, y uno de los asiduos asistentes a sus juntas, en las que coincidió con Luis Salvador Carmona en más de una ocasión.

Tiburcio de Aguirre pertenecía a una familia de rancio abolengo y origen vasco-navarro, con importantes dignatarios vinculados a la Corona desde tiempos de los Reyes Católicos, además de ilustres prohombres de la Iglesia y las órdenes militares de Santiago y Alcántara ${ }^{10}$.

8 Archivo Histórico Nacional (en adelante, AHN), Clero, Leg. 6243, s.f., 23 de septiembre de 1807.

9 AHN, Clero, Leg. 6243, s.f., 9 de octubre de 1749.

10 La relación con la Corona en tiempos de los RR.CC. en VIDAL-ABARCA, Juan, "Linajes Alaveses. Los Aguirre: Marqueses de Montehermoso", en Boletín de la Institución Sancho El Sabio, n. ${ }^{\circ} 19$, Vitoria, 1975, pp. 225226; 187. En lo que respecta a las filas de la iglesia y las 00.MM.: Real Academia de la Historia, Colección
Natural de Vitoria, don Tiburcio era el segundo hijo varón del matrimonio formado entre Francisco Antonio de Aguirre y Salcedo (16851745), II marqués de Montehermoso, y María Lorenza Ayanz de Arbizu y Lodosa (1687-?); y heredero, a su vez, de una tradición familiar que había permitido a los Aguirre estrechar sus lazos con la Corona y convertirse en miembros de la corte con plena confianza entre la familia real. Así se desprende del nombramiento que recibió en noviembre de 1759 como preceptor del futuro Carlos IV (1748-1819) ${ }^{11}$, al igual que su padre lo había sido del aún príncipe Carlos III (1716-1788) -1723-1731212 y su abuela, doña María Antonia de Salcedo (†1737), I marquesa de Montehermoso, del futuro Luis I (1701-1724) y de un recién nacido Carlos III en calidad de aya -respectivamente, 1707-1715 y $1716-1723^{13}-$. En este ambiente cortesano

Pellicer, t.III, 9/4057, f. 9r; CADENAS Y VICENT, Vicente de, Caballeros de la Orden de Alcántara que efectuaron sus pruebas de ingreso durante el siglo XVIII, t.I: núms. 1-134, Hidalguía, Madrid, 1991, pp. 24-26.

${ }^{11}$ Fue nombrado preceptor del príncipe por R.0. de 5 de noviembre de 1759: ROJAS CONTRERAS, José de, Historia del Colegio Viejo de S. Bartolomé, Mayor de la Celebre Universidad de Salamanca. Segunda Parte. Tomo Primero, Por Andrés Ortega, Madrid, 1768, p. 775.

12 El decreto está fechado el 12 de agosto de 1723, en que fue nombrado "Primer Gentilhombre del señor Ynfante Don Carlos y Theniente de Gouernador de Su Alteza": Archivo General de Palacio (en adelante, AGP), Personal, Caja 24, Exp. 5, foliado en parte, nombramiento de 14 de agosto de 1723. Vid., etiam, ÁLVAREZ Y BAENA, José Antonio, Hijos de Madrid, ilustres en santidad, dignidades, armas, ciencias y artes, t.II, En la Oficina de D. Benito Cano, Madrid, 1790, p. 242.

13 El título de marquesa de Montehermoso le fue concedido a instancias de la reina María Luisa de Saboya (1688-1714) en 1708 -aunque no se hizo efectivo hasta el real despacho de 14 de diciembre de 1714- como recompensa a los servicios prestados: VIDAL-ABARCA, Juan, Linajes Alaveses..., opus cit., pp. 220-221. La buena relación que la marquesa tenía con los reyes se desprende de la asiduidad con la que Felipe V se alojaba en el palacio de los Aguirre, en Vitoria, como lo hizo cuando entró por Irún el 24 de enero de 1701 para su proclamación: VIVES CASAS, Francisca, El palacio de Montehermoso. Historia de un edificio, Centro Cultural Montehermoso, Vitoria-Gasteiz, 2008, p. 40 y nota 18. Asimismo, y "en atenzion al expecial y apreciable merito que la Marquesa de Monteermoso ha hecho en la vigilante y prudente asistencia y educazion del Señor Principe Don Luis Fernando", Felipe V la recompensó con el nombramiento de su hijo Francisco Antonio de Aguirre - padre de Tiburcio de Aguirre- como mayordomo de semana de la reina Isabel de Farnesio por R.D. de 25 de marzo de 1715: AGP, Personal, Caja 24, Exp. 05, foliado en parte, 25 de marzo de 1715. Con posterioridad sería nombrado consejero de Indias por R.D. de 7 de octubre de 1731: AGP, Personal, Caja 24, Exp. 05, 
se había criado nuestro personaje, en el viejo alcázar madrileño, con su abuela y junto a su hermana pequeña Teresa Rosalía ${ }^{14}$.

Aguirre contaba solo siete años de edad cuando Felipe V (1683-1746) contrajo matrimonio en segundas nupcias -diciembre de 1714con Isabel de Farnesio; debió vivir muy de cerca la relación personal que la reina entabló con M. ${ }^{a}$ Antonia de Salcedo a su llegada a la corte española, a quien nombró primero su dama de honor (1715), confió después el cuidado de su primogénito, y otorgó posteriormente el cargo de guarda mayor de palacio (1725) ${ }^{15}$, haciendo posible con ello que nuestro personaje pudiera vivir desde niño su inclinación por la cultura y frecuentar el círculo artístico italiano del que se había rodeado -conocido entonces como el clan de los italianos-. Fue en ese entorno donde Tiburcio de Aguirre aprendió a hablar tanto en el idioma del país alpino como en francés, y seguramente recibió también las primeras nociones para practicar el dibujo con la afición

foliado en parte, fol. 8r. Sobre las fechas aportadas con los períodos en los que estuvo a cargo de Luis I y Carlos III siendo niños: AGP, Personal, Caja 697, Exp. 14, s.f., memorial de la marquesa de Montehermoso, fechado en 1734.

14 ROJAS CONTRERAS, José de, Historia del Colegio..., opus cit., pp. 772 y 778. Vives Casas reproduce un grabado francés con la I marquesa de Montehermoso en la corte, sosteniendo al príncipe y futuro Luis I rodeada de distintos miembros de la nobleza: VIVES CASAS, Francisca, El palacio de Montehermoso..., opus cit., p. 42.

15 VIDAL-ABARCA, Juan, Linajes Alaveses..., opus cit., p. 220. La propia marquesa se refería al cuidado del recién nacido Carlos III en el memorial que remitió a la reina en 1734 solicitando "los onores de grande" para ella y su descendencia; y aunque su vínculo con Carlos III es conocido, la cita que sigue a continuación permite constatar el estrecho lazo de amistad y confianza que tenía con la familia real: "V.M. se sirvió de haçerme la onrra de poner a mi cuidado desde que nacio el Rey de Napoles y fiarme su asistencia y educacion en sus primeros años, y hauiendo proseguido mi hijo, en casi ygual encargo por la muerte del duque de San Pedro [Francisco M. ${ }^{a}$ Spínola Spínola, 1660-1727, quien había estado al frente del grupo de hombres a quienes se encomendó la educación del príncipe], asta el viaje de su Magestad á Ytalia [1731] que pasaron quinçe años y nuebe Meses salió su Magestad de las manos de ambos tan sin aiar ni malos resabios y con ydeas correspondientes a los progresos de su grande espíritu y que tan dignamente le a merecido que la benignidad y Amor del rey le ayan exaltado ya a la corona de Napoles [...]: AGP, Personal, Caja 697, Exp. 14, s.f., memorial fechado en 1734. El cargo de guarda mayor de palacio en AGP, Personal, Caja 697, Exp. 14, s.f., según consta en la participación que se le hizo al marqués de San Juan el 23 de abril de 1725. que Ceán Bermúdez (1749-1829) recogió, y 45 ponderó al ser uno de los pocos consiliarios que tuvo la Academia de San Fernando aficionados a su práctica. Aguirre llegaría a convertirse en un firme defensor de la enseñanza reglada del dibujo, según declaraba en $1753^{16}$. Desde luego, el entorno era propicio para ello, y así se desprende de la dedicatoria que Antonio Palomino (1655-1726) le hizo a Isabel de Farnesio del primer tomo de su conocido Museo pictórico $y$ escala óptica $(1715)^{17}$, aprovechando el trabajo que entonces realizaba para ornamentar el alcázar de los Austrias. Asiduo desde niño a este mundo, no es de extrañar que Tiburcio de Aguirre lograra "la satisfaccion de merecer el agrado de sus Altezas Serenisimas, y demás Señores Infantes" siendo preceptor de Carlos IV; una situación de la que se infiere la íntima relación de confianza que le posibilitó -entre otras cosas- organizar en palacio la sesión de reparto de premios que la Academia de San Fernando celebró en 1753, o incluso que hiciera alusión a aspectos particulares y hasta personales de los reyes en la correspondencia que mantuvo con su primo el duque de Granada entre los años 1757 y $1759^{18}$.

Don Tiburcio continuó su formación en la Universidad de Alcalá de Henares durante los

${ }_{16}$ El aprendizaje de los idiomas y su afición al dibujo los recoge ROJAS CONTRERAS, José de, Historia del Colegio..., opus cit., p. 772; CEÁN BERMÚDEZ, Juan Agustín, Diccionario Histórico de los más ilustres profesores de las Bellas Artes en España, En la Imprenta de la Viuda de Ibarra, Madrid, 1800, t.I, p. 8. Sobre su práctica del dibujo vid., etiam, BÉDAT, Claude, La Real Academia de Bellas Artes de San Fernando (17441808), Fundación Universitaria Española y Academia de San Fernando, Madrid, 1989 (2 ${ }^{\mathrm{a}}$ ed.; la primera es de 1974), p. 183. En cuanto a la defensa de la enseñanza del dibujo, VEGA, Jesusa, Ciencia, arte e ilusión en la España Ilustrada, CSIC-Polifemo, Madrid, 2010, p. 229.

17 LAVALLE-COBO, Teresa, "Isabel de Farnesio, la pasión por el arte”, en AA.VV., La mujer en el arte español, Alpuerto, Madrid, 1997, p. 220. El interés de la reina por la cultura y el coleccionismo está recogido en la carta que escribió en Aranjuez poco antes de morir recordando su vida: ÍDEM, Isabel de Farnesio. La reina coleccionista, Fundación de Apoyo a la Historia del Arte Hispánico, Madrid, 2002, pp. 23-27.

18 La cita textual en ROJAS CONTRERAS, José de, Historia del Colegio..., opus cit., p. 775. Los premios de 1753 en: TÁRRAGA BALDÓ, M. ${ }^{a}$ Luisa, Giovan Domenico Olivieri y el taller de escultura del Palacio Real, t.I: Biografía, Patrimonio Nacional y CSIC, Madrid, 1992, p. 157, nota 372. En la citada correspondencia con su primo el duque de Granada vemos que estaba al día, por ejemplo, de los traslados de los reyes (carta de 8 de junio de 1757): Archivo del Monasterio de las Descalzas Reales de Madrid, Caja 79, Exp. 50, ff. 11r-11v. 
cursos 1724/25 y 1725/26, iniciando sus estudios de Teología ${ }^{19}$, aunque será en la Universidad de Salamanca donde alcance, no obstante, el título de licenciado en Cánones. Para ello, y siguiendo la tradición de su familia, se matriculó en el colegio mayor de San Bartolomé para acudir a la Facultad de Cánones durante los once cursos transcurridos entre 1729/30 y 1739/40, último en el que figura; y como licenciado lo hace ya desde $1733^{20}$. Es importante destacar que en el marco de esta etapa formativa fue nombrado, a instancias del segundo director e hijo del fundador de la Real Academia Española, Mercurio Antonio López Pacheco (1679-1738), miembro honorario de dicha institución en 1735, supernumerario el 14 de mayo de 1737, y académico de número en 1744 $(\text { Silla } S)^{21}$. Este nombramiento le permitió entrar en contacto con el grupo de reformadores ilustrados a los que recurrió en 1750 el ministro de estado José de Carvajal y Lancáster (16981754) al objeto de fundar la Academia de Bellas Artes de San Fernando ${ }^{22}$, institución en la que estrechó sus lazos de amistad con Luis Salvador Carmona, según veremos.

Fue en Salamanca donde Tiburcio de Aguirre empezó a dar muestras del afán coleccionista que le acompañó durante toda su vida, fruto de

19 AHN, Universidades, Leg. 435, Exp. 160, certificaciones de 4 marzo de 1725 y 16 de marzo de 1726 , donde consta que cursó las cátedras de Suma (1725) y de Lógica (1726).

20 Archivo de la Universidad de Salamanca (en adelante, AUSA), Matrícula del Curso 1729-1730, sign. ${ }^{a}$ AUSA, 437, f. 17r.; Matrícula del Curso 1730-1731, sign. ${ }^{a}$ AUSA, 438, f. 13r; Matrícula del Curso 1731-1732, sign. ${ }^{a}$ AUSA, 439, f. 14v; Matrícula del Curso 17321733, sign. a AUSA, 440, f. 18v; Matrícula del Curso 1733-1734, sign. ${ }^{a}$ AUSA, 441, f. 13r; Matrícula del Curso $1734-1735$, sign. ${ }^{a}$ AUSA, 442, f. 13v; Matrícula del Curso 1735-1736, sign. a AUSA, 443, f. 18r; Matrícula del Curso 1736-1737, sign. a AUSA, 444, f. 13r; Matrícula del Curso 1737-1738, sign. ${ }^{a}$ AUSA, 445, f. 16r; Matrícula del Curso 1738-1739, sign. ${ }^{a}$ AUSA, 446, f. 10v; Matrícula del Curso 1739-1740, sign. a AUSA, 447, f. 11r. El título de licenciado consta a partir del curso 1733-1734: AUSA, Matrícula del Curso 1733-1734, sign. ${ }^{a}$ AUSA, 441, f. 13r. Un resumen de los datos expuestos, aunque sin explicitar las referencias archivisticas exactas y sin recoger la titulación de licenciado: CARABIAS TORRES, Ana M. a, "Catálogo de colegiales del Colegio Mayor de San Bartolomé (1700-1840)”, en Studia Historica. Historia Moderna, vol. IX, Salamanca, 1991, p. 59.

21 ZAMORA VICENTE, Alonso, Historia de la Real Academia Española, Espasa-Calpe, Madrid, 1999, p. 90; $<$ http://www.rae.es/academicos/tiburcio-de-aguirre-salcedo $>$ [consulta: 7/5/2016].

22 BÉDAT, Claude, La Real Academia..., opus cit., p. 70. lo que había conocido en palacio siendo niño, y de la nueva orientación experimental que había empezado a arraigar en Europa en el campo del conocimiento científico, proyectada en España a través de un pujante movimiento preilustrado que pronto arraigó en regiones, precisamente, como la vasca. Su "genio curioso" por las matemáticas y la física experimental le llevó a iniciar una importante "Coleccion de Maquinas, Instrumentos Phisicos y Mathematicos [...] que iba juntando con tanta prolixidad como gusto"; y a reunir un gabinete de historia natural, cuya importancia se desprende de la orden que dictó al poco de su muerte el aún príncipe Carlos IV para que fuera adquirido e integrado en el proyecto que tenía el agustino Enrique Flórez (1702-1773) de formar el Real Gabinete de Historia Natural $^{23}$. Se sumaba la amplia, escogida y selecta biblioteca junto al monetario que atesoró en su propio museo ${ }^{24}$; y el gusto que tuvo por la pintura, a cuya colección perteneció el cuadro de la Virgen con el Niño que el profesor Diego Angulo Íñiguez (1901-1986) recogió en 1980 entre las obras atribuidas a Murillo, hoy

${ }^{23}$ La nueva orientación del pensamiento científico y su proyección y arraigo en España en ASTIGARRAGA, Jesús, Los ilustrados vascos. Ideas, instituciones y reformas económicas en España, Barcelona, Crítica, 2003, pp. 23-35, passim. La cita textual en ROJAS CONTRERAS, José de, Historia del Colegio..., opus cit., pp. 772 y 776. Por orden real el gabinete se lo adquirió el duque de Béjar al marqués de Montehermoso, heredero de Tiburcio de Aguirre, el 24 de julio de 1767: ESPINOSA MARTINI, M. ${ }^{a}$ del Carmen, "Aportes documentales a los bodegones de Luis Meléndez”, en Boletín del Museo del Prado, n. ${ }^{\circ}$ 10, Madrid, 1989, pp. 69, donde consta que su importe ascendió 6.137 reales y 32 maravedís; y p. 74, nota 15, donde figura la referencia a partir del Archivo General de Palacio. Sobre el proyecto de formar el Real Gabinete de Historia Natural, vid. CAMPOS Y FERNÁNDEZ DE SEVILLA, F ${ }^{\text {co }}$ Javier, "Relación del agustino Enrique Flórez con la Familia Real (17491772)", en Anuario Jurídico y Económico Escurialense, Volumen XLIV, San Lorenzo de El Escorial, 2011, p. 542; LÓPEZ VIDRIERO, M. a Luisa y CÁTEDRA, Pedro M., El Libro Antiguo Español. III. El Libro en Palacio y otros Estudios Bibliográficos, Ediciones Universidad de Salamanca, Patrimonio Nacional y Sociedad Estatal de Historia del Libro, Salamanca, 1996, p. 180.

24 La biblioteca en ROJAS CONTRERAS, José de, Historia del Colegio..., opus cit., pp. 772 y 776. Sobre el monetario vid. MUÑIZ, Fr. Roberto, S.O.Cist., Biblioteca Cisterciense Española. En la que se dan Noticia de los Escritores Cistercienses de todas las Congregaciones de España, y de los de las Ordenes Militares que siguen el mismo Instituto..., Por Don Joseph de Navas, Burgos, 1793, p. 7; MAIER ALLENDE, Jorge, Noticias de Antigüedades de las Actas de Sesiones de la Real Academia de la Historia (1738-1791), Real Academia de la Historia, Madrid, 2011, pp. 269-270. 
conocida a través de la estampa que Manuel Salvador Carmona (1734-1820) grabó en 1763 y le dedicó a su propietario, tal vez en agradecimiento del informe que éste había emitido a su favor en agosto de 1760 para encomendarle el proyecto del rey de poner en talla dulce la genealogía de la casa real. Aguirre también contaba en su colección con la tabaquera, los sellos y la escribanía que Ceán Bermúdez recogió y ponderó entre las mejores obras del grabador en hueco, procedente de Sicilia, Lorenzo Monteman y Cusens $(+1760)^{25}$.

Una vez concluidos sus estudios en Salamanca, Tiburcio de Aguirre inició una fulgurante carrera en el Consejo Real de Navarra, para el que fue promovido por el rey en marzo de 1740 en calidad de "Alcalde de la Corte Mayor de aquel Reyno”, y en el que desempeñó distintas ocupaciones ${ }^{26}$ hasta 1746 , año de su retorno a Madrid -el mismo en el que tuvo lugar la repentina muerte de Felipe V, circunstancia que de algún modo debió mediar para que fuera reclamada su presencia- e ingreso en la Real Congregación de San Fermín de los Navarros, donde asistió como testigo a la empresa

25 ANGUlo ÍÑIGUEZ, Diego, Murillo. Tomo II. Catálogo crítico, Espasa-Calpe, Madrid, 1981, pp. 155-156 (n ${ }^{\circ}$ 158) y p. 405 (n'1.097); ÍDEM, Murillo. Tomo III. Láminas, Espasa-Calpe, Madrid, 1981, lám. 531. La cita del informe de 1760 la tomo de PÉREZ BUENO, L., "Grabadores de monedas y medallas, años de 1760 a 1799. Documentos del Archivo Nacional de Simancas”, en Archivo Español de Arte, Volumen XX, n. ${ }^{\circ}$ 80, Madrid, 1947, p. 306. Vid., etiam, CEÁN BERMÚDEZ, Juan Agustín, Diccionario..., opus cit., t.III, p. 175. Su interés por la pintura también le llevó a seguir muy de cerca la conformación de la colección de la Real Academia de San Fernando, según se desprende de la carta que don Tomás de Azpuru (1770-1772), embajador de España ante la Santa Sede, le envió a Aguirre en 1767 participándole el envío que hacía desde Roma de un cuadro con el tema de Hércules: URREA, Jesús, Relaciones artísticas hispano-romanas en el siglo XVIII, Fundación de Apoyo a la Historia del Arte Hispánico, Madrid, 2006, pp. 189 y 229 (nota 67).

26 El nombramiento de alcalde de Corte está recogido en la Gaceta de Madrid, n. ${ }^{\circ}$ 13, 29/03/1740, p. 103. El 22 de julio de 1744 fue nombrado vocal de la Junta de apelaciones, que llevaba a cabo el juez conservador de la renta del tabaco de Navarra en casos de fraude; en el mes de septiembre de ese mismo año fue ascendido a oidor del Consejo de Navarra, y un mes después recibió el nombramiento de juez comisario del derecho de la media annata: SESÉ ALEGRE, José M. ${ }^{a}$, El Consejo Real de Navarra en el siglo XVIII, Eunsa, Pamplona, 1994, pp. 299-300. En su nombramiento como oidor del Consejo navarro, tenemos constancia de la confianza que el rey tenía "en la suficiencia[,] letras y buena conciencia" del "licenciado D. Tiburcio Phelipe de Aguirre": AHN, Consejos, Libro 736, fol. 399r. escultórica que Luis Salvador Carmona iniciaba entonces para ornamentar la iglesia de dicha congregación ${ }^{27}$. Asimismo, y en recompensa por los servicios que habian prestado a la Corona tanto su abuela como su padre, Fernando VI le promovió al Consejo Real y Supremo de las Órdenes Militares, en el que ingresó en 1748 tras alcanzar la cédula de merced del hábito de la Orden de Alcántara el 14 de noviembre de 1747, y el título por cédula de 21 de mayo de $1748^{28}$. Este mismo año fue nombrado capellán mayor del Real Convento de las Descalzas Reales de Madrid, cargo que desempeñó hasta su muerte en 1767. También se sumaron "el empleo de Sumiller de Cortina" (24 de abril de 1754), que juró el 13 de mayo siguiente; el título de marqués de Fuentehermosa que aparece recogido en el archivo de las Descalzas Reales; y el patronazgo del Real Convento de San Pedro en la villa de Brozas, que debió ostentar desde su designación como ministro del Consejo de las Órdenes Militares ${ }^{29}$.

En este último nombramiento debió mediar la relación que la familia Salcedo había tenido con Extremadura a finales del siglo XVII, cuando don Antonio Ildefonso de Salcedo y Arbizu (†1689), bisabuelo de don Tiburcio, fue

27 IMÍZCOZ BEUNZA, José M. ${ }^{\text {a, }}$ "Los navarros en la Corte. La Real Congregación de San Fermín (1683-1808)”, en GARCÍA GARCÍA, Bernardo J. y RECIO MORALES, Óscar, Las corporaciones de nación en la monarquía hispánica (1580-1750). Identidad, patronazgo y redes de sociabilidad, Fundación Carlos de Amberes, Madrid, 2014, p. 157. Sobre la intervención de Carmona: SAGÜÉS AZCONA, Pío, OFM, La Real Congregación de San Fermin de los Navarros (1683-1961) (Estudio histórico), Gráficas Canales, Madrid, 1963, pp. 168-174; GARCÍA GAÍNZA, M. ${ }^{a}$ Concepción, Luis Salvador Carmona en San Fermin de los Navarros, Real Congregación de San Fermín de los Navarros, Madrid, 1990, pp. 27-28.

28 CADENAS Y VICENT, Vicente. de, Caballeros de la Orden de Alcántara..., opus cit., p. 24.

29 Su nombramiento como capellán de las Descalzas fue una decisión personal del monarca, el cual se hizo efectivo el 18 de junio de 1748: ROJAS CONTRERAS, José de, Historia del Colegio..., opus cit., p. 773; VILACOBA RAMOS, Karen M. ${ }^{a}$, El monasterio de las Descalzas Reales y sus confesores en la Edad Moderna, Vision Libros, Madrid, 2013, p. 114. El cargo de Sumiller en AGP, Personal, Caja 12398, Exp. 04, s.f.; y en ROJAS CONTRERAS, José de, Historia del Colegio..., opus cit., p. 774. El título de marqués de Fuentehermosa en GARCÍA LÓPEZ, Consuelo, Inventario de los Fondos Documentales de los Reales Patronatos. Tomo I. Archivo del Monasterio de las Descalzas Reales de Madrid, Patrimonio Nacional, Madrid, 2004, p. 225; y el de patrono del convento brocense en AHN, Clero, Leg. 6243, s.f., 9 de octubre de 1749 . 
nombrado caballero alcantarino y gobernador del partido de La Serena ${ }^{30}$, a la sazón el gran núcleo del señorío de la Orden junto a la villa de Alcántara. Sin embargo, a mediados del siglo XVIII el Real Consejo atravesaba un período de cierta decadencia, situación que se trató de paliar, entre otras medidas, con la puesta al día de los derechos y concesiones reales y papales adquiridos a lo largo de los siglos a fin de procurar una mejor defensa de sus territorios y afianzar la autoridad que ejercía sobre ellos; por tal motivo, entre 1747 y 1749 el Consejo ordenó imprimir las definiciones de la Orden de Calatrava y la Crónica de Alcántara que frey Alonso de Torres y Tapia (1578-1638) había escrito en el siglo anterior y aún se hallaba manuscrita. Fernando VI otorgó la preceptiva licencia para este proceder en noviembre de 1754, cinco años después de haber elevado la solicitud, y el cometido recayó en Tiburcio de Aguirre, quien daría el proceso por concluido en 1763 no sin antes dedicar la edición al príncipe y futuro rey Carlos IV, de quien era preceptor $^{31}$. También le fue encargada la composición e impresión de los bularios de las órdenes de Alcántara y Calatrava, de lo que se infiere que nuestro personaje "tuvo campo para acreditar su literatura, y prendas" en el Consejo ${ }^{32}$.

En el intento por revitalizar el Real Consejo de las Órdenes Militares hay que situar también el patronato que Tiburcio de Aguirre aceptó ejercer sobre el convento brocense de San Pedro a mediados del siglo XVIII, decisión en la que debió influir el hecho de ser uno de los pocos caballeros alcantarinos que había entonces en el mismo -de hecho, en 1763 era el único ${ }^{33}$-,

30 ARTIGAS Y COROMINAS, Pelayo, Los Salcedos y los Ríos Progenitores de los Condes de Gómara, Tip. de la "Revista de Archivos, Bibliotecas y Museos", Madrid, 1920, p. 13.

31 LÓPEZ DE ZUAZO Y ALGAR, José M. ; MARTÍN NIETO, Dionisio y MIRANDA DÍAZ, Bartolomé, Estudio crítico de la edición y continuación de la Crónica de la Orden de Alcántara, Parlamento de Extremadura, Mérida, 2014, pp. 92-94; TORRES Y TAPIA, Fr. Alonso de, Cronica de la Orden de Alcantara, En la Imprenta de Don Gabriel Ramirez, Impresor de la Real Academia de San Fernando, Madrid, 1763, t.I, pp. I-IV; BARRANTES, Vicente, Aparato Bibliográfico para la Historia de Extremadura, t.III, Establecimiento Tipográfico de Pedro Núñez, Madrid, 1877, pp. 243-244.

32 El bulario de Calatrava se puso bajo su dirección por el fallecimiento de don Ignacio Ortega, a quien le había sido encargado: ROJAS CONTRERAS, José de, Historia del Colegio..., opus cit., p. 774.

33 BARRANTES, Vicente, Catálogo razonado y crítico de los Libros, Memorias y Papeles, impresos y manuscri- y el que dicho convento estuviera situado en la villa de Brozas, al amparo de la protección del castillo donde residía el comendador mayor de la Orden. El monasterio había sido fundado en los años mediales del siglo XVI a instancias de frey don Pedro Gutiérrez Flores, capellán de su majestad, sacristán mayor de la Orden y natural de la villa de las Brozas, tras obtener la licencia que Felipe II le otorgó en Toledo el 10 de mayo de $1561^{34}$. Durante la primera mitad del siglo XVIII, las monjas habían tenido que hacer frente a diversas vicisitudes y acometer continuos reparos en la iglesia hasta que el rey aceptó hacerse cargo de la fábrica en septiembre de $1744^{35}$. Ante el avance con el que se desarrollaron los trabajos, la comunidad decidió hacer un nuevo tabernáculo para engalanar el templo y adecentar la exposición del Santísimo Sacramento. La escritura de concierto se firmó el 20 de diciembre de 1747 con el maestro de arquitectura y talla, procedente de Trujillo, Bartolomé Jerez, y se ajustó en un total de 3.000 reales de vellón; los 190 reales que éste recibió el 20 de mayo de 1748 "por gratificación que le hizo la comunidad por la obra de el tabernáculo", permiten constatar que ya estaba terminado, al igual que el marco de altar por el que recibió 150 reales en la fecha referida. Así lo describía en su carta fray Antonio Calderón y Robles, capellán del convento de San Pedro, cuando se remitió al patrono del mismo con fecha de 9 de octubre de 1749 para comunicarle que las

tos, que tratan de las provincias de Extremadura, asi tocante á su Historia, Religión y Geografía, como a sus Antigüedades, Nobleza y Hombres Célebres, Imp. y Estereotipia de M. Rivadeneyra, Madrid, 1865, p. 250.

34 Archivo Histórico Provincial de Cáceres (en adelante, AHPCC), Clero, Leg. 5, Exp. 10, s.f., "Escritura de fundación (1561-1747)”. Vid., etiam, ZAPATER, Miguel Ramón, Cister Militante en la Campaña de la Iglesia contra la Sarracena furia. Historia general de las Ilustrisimas, Inclitas y Nobilisimas Cauallerias del Templo de Salomon, Calatraua, Alcantara, Avis, Montesa, y Christo, Por Agustín Verges, Zaragoza, 1662, p. 480. También recoge la referencia sobre la fundación, aunque sin citar la procedencia del documento, CARRASCO MONTERO, Gregorio, “Comendadoras de Alcántara -rama femenina de la Orden- en las Brozas", en AA. VV., XXXI Coloquios Históricos de Extremadura, C.I.T. de Trujillo, Badajoz, 2003, p. 112.

35 DIEZ GONZÁlEZ, M. ${ }^{a}$ del Carmen, "Proyecto de restauración de la capilla del Convento de las Monjas Comendadoras para Auditorio Municipal. Brozas (Cáceres). Fases I y II", en Boletín de Arte, n. ${ }^{\circ} 29$, Málaga, 2008, pp. 118-119; ÍDEM, "Propuesta de reforma en la iglesia del convento de San Pedro de Brozas (Cáceres) por Theodosio Magalães”, en Norba. Revista de Arte, Volumen XXVI, Cáceres, 2006, p. 263. 
monjas habían asumido la ejecución del tabernáculo "en medio de su gran pobreza", y que no se había podido dorar por la grave falta de recursos que padecían ${ }^{36}$. Si a esta circunstancia añadimos que el rey ya había acudido en su ayuda haciéndose cargo de la obra de la iglesia, solo nos resta pensar que fue Tiburcio de Aguirre quien costeó la obra de Ntra. Sra. del Socorro. La talla vendría a ser el corolario a un largo proceso de remodelación, y también debió ser un intento por revitalizar una comunidad que entonces se hallaba reducida a las seis monjas que se recogen en el catastro de la Ensenada en 1753, frente a las veintidós religiosas que el convento podía albergar ${ }^{37}$.

En la visita que Manuel Baltasar de Arce y Paredes, cura rector de la iglesia parroquial de Brozas, y frey Francisco Antonio Calderón y Robles, caballero y religioso de la Orden de Alcántara, hicieron al convento en 1750 se recoge una detallada descripción del recién construido tabernáculo, pero no hay referencia alguna a la escultura mariana. Es de imaginar por tal razón que su encargo fue posterior al informe que la comunidad elevó al patrono el 21 de mayo de 1751 dando cuentas del estado en el que se encontraba el convento ${ }^{38}$; y que dicho ajuste no fue muy posterior a la licencia que el rey concedió en noviembre de 1754 para proceder a la impresión de la Crónica de la Orden alcantarina. Estaríamos hablando, pues, de una horquilla temporal comprendida entre mayo de 1751 y finales del año 1754 o inicios del siguiente, por lo que se confirma plenamente la hipótesis que Martín González aportó en 1990 sobre la datación de la pieza, que situaba en torno a 1750 y en plena correspondencia con las esculturas de la Virgen del Rosario conservadas en la parroquia vergaresa de Santa Marina (Vergara, Guipúzcoa, 1742) y la iglesia navarra de Santesteban (1746 o 1752); la Asunción de Serradilla (Cáceres, 1749); o la tardía escultura

36 AHN, Clero, Leg. 6243, s.f., escrituras 20 de diciembre de 1747; 20 de mayo de 1748; y 9 de octubre de 1749.

37 Archivo General de Simancas, Catastro de la Ensenada, Respuestas Generales, Libro 136, f. 225r, 11 de mayo de 1753. La capacidad del convento la tomo de CARRASCO MONTERO, Gregorio, “Desamortización del Real Convento de San Pedro de las Comendadoras del hábito y caballería de la Orden de Alcántara en la encomienda mayor de las Brozas (Cáceres)”, en Memoria Ecclesiae, Volumen 23, Madrid, 2003, p. 372.

38 AHN, Clero, Leg. 6244, foliado en parte, Visita de 1750, fechada el 27 de noviembre de 1750, ff. 116v-118r; y escritura de 21 de mayo de 1751. de Ntra. Sra. del Patrocinio (1765) conservada en el santuario de Loyola (Guipúzcoa) ${ }^{39}$. Tiburcio de Aguirre acudió para ello al taller de Luis Salvador Carmona, a quien debía conocer muy bien porque ambos estuvieron presentes en el proceso de creación de la Real Academia de Bellas Artes de San Fernando.

Ambos figuran en la real orden por la que Felipe V sancionó su creación el 12 de abril de 1752, nombrando a Tiburcio de Aguirre entre los seis consiliarios - el "alma"- de la misma y a Luis Salvador teniente director de escultura (1752-1765). El protagonismo que tuvo nuestro personaje en la creación de la Academia se justifica por su amplio bagaje cultural, y se desprende del activo papel que jugó en la elaboración de los estatutos de 1746, y del hecho de haber sido uno de los miembros honoríficos del proyecto que el crítico y escritor Ignacio Luzán (1702-1754) redactó en 1750 para su creación ${ }^{40}$; un papel protagonista que siempre desempeñó mirando hacia la Corona ${ }^{41}$. La im-

39 Un estudio de la escultura, a partir del trabajo citado de Martín González, en TORRES PÉREZ, José M.a, "Bartolomé de Jerez y Luis Salvador Carmona en el retablo de la iglesia parroquial de Brozas (Cáceres)”, en Norba-Arte, Volumen XVI, Cáceres, 1996, pp. 397-400.

40 BÉDAT, Claude, La Real Academia..., opus cit., pp. 6869 y 182, donde se recogen los nombramientos; p. 75, en lo que respecta a la elaboración de los estatutos; y p. 70, para el proyecto de Ignacio Luzán. Teniendo en cuenta la experiencia e influencias que Aguirre tenía, en diciembre de 1764 le fueron enviados, por su sobrino el IV marqués de Montehermoso y el conde de Peñaflorida, los estatutos de la Real Sociedad Bascongada de los Amigos del País (en adelante, RSBAP) para que realizara las gestiones necesarias en orden a su aprobación por el rey (1765), convirtiéndose de este modo en el impulsor de iniciativas que fueron claves para la consolidación de la institución, como la publicación del Ensayo de 1766 que citamos a continuación y donde consta el papel que jugó en la aprobación de los estatutos; por todo ello, fue nombrado socio protector de la Sociedad en 1765, recibiendo sus elogios: Ensayo de la Sociedad Bascongada de los Amigos del País. Año 1766, por Thomás de Robles, Vitoria, 1768, s/p.; ORTÍZ DE URBINA MONTOYA, Carlos, "Amistad, jerarquía y exclusión en los primeros años de la Sociedad Bascongada de los Amigos del País", en Boletín de la RSBAP, Volumen LXII.2, San Sebastián, 2006, pp. 349 (y nota 18), 352 y 361 (donde recoge el nombramiento como socio protector el 18 de abril de 1765). Vid., etiam,

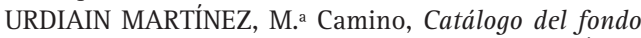
prestamero. Archivo del territorio histórico de Álava (ATHA), RSBAP, Vitoria, 1996, p, 116, §175.9, donde consta la referencia archivística sobre el Elogio a la memoria de Tiburcio de Aguirre.

${ }^{41}$ Sobre el instrumento que suponía la Academia en el organigrama político de la monarquía, y la sujeción de Aguirre a la Corona, véase LEÓN TELLO, F. ${ }^{\text {co }}$ José 
plicación de Aguirre en la actividad académica justifica, entre otros aspectos, la dedicatoria que le hizo Hermenegildo Víctor Ugarte y Gascón (1735-después de 1768), discípulo pensionado de San Fernando, en la letra del grabado que estampó en 1756 con la imagen del madrileño puente de Toledo sobre el río Manzanares; o las instrucciones que redactó en 1766, junto a José de Hermosilla (1715-1776), con los objetivos para materializar el proyecto de delinear las antigüedades árabes de Córdoba o Granada, y que acometieron el mismo Hermosilla, Juan de Villanueva (1739-1811) y Juan Pedro Arnal (1735-1805) entre 1766 y $1767^{42}$.

Tiburcio de Aguirre fue nombrado viceprotector de la Academia el 27 de abril de 1753, cargo que desempeñó hasta su muerte. El celo que puso en su desempeño se sustancia en la abundante correspondencia conservada y relacionada con asuntos académicos de lo más diverso, y del hecho de haber presidido doscientas diez juntas de las doscientas sesenta que se celebraron cuando era viceprotector, lo que sin duda le permitió un manejo mucho más efectivo de la institución ${ }^{43}$. El hecho de figurar junto a Salvador Carmona en la real orden por la que Felipe V fundaba la Academia, y el haber coincidido con el escultor en las distintas

y SANZ SANZ, M. ${ }^{a}$ Virginia, Estética y Teoría de la Arquitectura en los tratados españoles del siglo XVIII, CSIC, Madrid, 1994, p. 174.

42 De la estampa de Ugarte y Gascón se conservan diversos ejemplares; citemos el de la Biblioteca Nacional de España (en adelante, BNE), INVENT/23532; y la Real Academia de Bellas Artes de San Fernando, Gr-541; recordemos que Aguirre también era un firme defensor del estudio del grabado: VEGA, Jesusa, Ciencia, arte..., opus cit., p. 391. Sobre el proyecto de las antigüedades árabes vid. GARCÍA SÁNCHEZ, Jorge, "La Real Academia de San Fernando y la Arqueología", en Academia, Núms. 106-107, Madrid, 2008, p. 31.

43 BÉDAT, Claude, La Real Academia..., opus cit., p. 36, nota 34, para el nombramiento como viceprotector; y p. 189, sobre el efectivo manejo que tuvo de la Institución desde aquel cargo, y de cuyo celo se hizo eco CEÁN BERMÚDEZ, Juan Agustín, Diccionario..., opus cit., t.I, p. 8. Sobre la citada correspondencia, véanse, por ejemplo, los escritos conservados en la Biblioteca de la Fundación Lázaro Galdiano: YEVES ANDRÉS, Juan Antonio, Manuscritos Españoles de la Biblioteca Lázaro Galdiano, t.II, Ollero \&t Ramos Editores - Fundación Lázaro Galdiano, Madrid, 1998, pp. 634-638, procedentes del manuscrito titulado Historia de las Bellas Artes. España, sign. ${ }^{a}$ M 31-12; PARDO CANALÍS, Enrique, La Real Academia de San Fernando, Ayuntamiento e Instituto de Estudios Madrileños del CSIC, Madrid, 1989, p. 25. juntas que se celebraron entre 1753 y $1765^{44}$, son datos objetivos que nos permiten constatar sin ninguna reserva que ambos se conocían muy bien. Aguirre era además un apasionado admirador de las Bellas Artes, y así lo manifestó en los discursos que ofreció en las sesiones públicas de reparto de premios celebradas por la Academia de San Fernando en 1753 -a la que ya nos hemos referido- y 1754, convocatoria esta última en la que llegó a ponderar la obra de escultores como Alonso Cano y Pedro de Mena ${ }^{45}$. Por tanto, no es desacertado pensar que Tiburcio de Aguirre acudiera al taller de Luis Salvador Carmona para encargarle la pieza destinada al convento del que era patrono; además, su nombramiento en 1752 como prefecto de la madrileña y Real Congregación de San Fermín de los Navarros es exponente de la relevancia que tenía nuestro personaje en el seno de la organización, y nos permite imaginar que debió seguir muy de cerca los sucesivos trabajos que el escultor hizo para la misma entre 1746 y $1747^{46}$, justo en el momento en que acababa de llegar a Madrid procedente del Consejo Real de Navarra. Y también es razonable pensar que en su decisión mediara la amistad que tenía con el grabador Manuel Salvador Carmona, sobrino del escultor.

Sin embargo, en su determinación de acudir al que ya entonces se había convertido en uno de los obradores más afamados de Madrid, debió influir de un modo muy especial la implicación que la reina Isabel de Farnesio tuvo en la ampliación de la iglesia de Nuestra Señora del Rosario, en San Ildefonso, con las dos capillas que mandó elevar en 1746 en el centro de am-

44 BÉDAT, Claude, Los Académicos y las Juntas 17521808, Real Academia de Bellas Artes de San Fernando, Madrid, 1982, pp. 18, 20, 23, 25-29, 31-36 y 38-40.

45 ÍDEM, La Real Academia..., opus cit., p. 189, donde el autor recoge la admiración de Aguirre por las Bellas Artes. Sobre las sesiones de reparto de premios: Distribucion de los Premios concedidos por el Rey N.S. A los Discipulos de las Tres Nobles Artes, Hecha por la Real Academia de San Fernando en la Junta general de 22 de diciembre de 1754, En la oficina de D. Gabriel Ramírez, Madrid, Año de M.DCC.LV., pp. 28-29; LEÓN TELLO, F. ${ }^{\text {co }}$ José y SANZ SANZ, M. ${ }^{a}$ Virginia, Estética $y$ Teoría..., opus cit., p. 188; CHOCARRO BUJANDA, Carlos, La búsqueda de una identidad. La escultura entre el gremio y la academia (1741-1833), FUE, Madrid, 2001, p. 233.

46 SAGÜÉS AZCONA, Pío, OFM, La Real Congregación..., opus cit., p. 316 (nombramiento como prefecto), y pp. 168-174 (obras de Luis Salvador); GARCÍA GAÍNZA, M. ${ }^{a}$ Concepción, Luis Salvador Carmona en San Fermin..., opus cit., pp. 27-28. 
bos lados del buque eclesial, y en señal de agradecimiento por el buen parto de su último hijo, el infante don Luis (1727-1785) ${ }^{47}$. Con este feliz acontecimiento es necesario relacionar también el encargo de la escultura del Cristo del Perdón que Luis Salvador talló para esa misma iglesia en 1751, porque en la letra del grabado que su sobrino Juan Antonio Salvador Carmona hizo en 1768 con la desgarradora efigie de Cristo, aparece el infante don Luis como hermano perpetuo y particular bienhechor de la cofradía de la Real Esclavitud ${ }^{48}$, lo que es necesario interpretar como el fruto de aquella promesa que su madre había hecho años atrás y ahora se materializaba. Si a esto sumamos que el Cristo del Perdón fue el titular del templo en un principio, podremos corroborar la idea que ya teníamos sobre la mediación que ejerció la reina en su encargo a través del pintor Domingo María Sani (1690-1773) ${ }^{49}$, quien estaba al frente de la construcción de la iglesia del Rosario, y había sucedido a su maestro Andrea Procaccini (1671-1734) -arquitecto romano de confianza para la reina- en el cargo de aposentador mayor de palacio. Tiburcio de Aguirre debió ser fiel testigo de un aspecto tan personal en la vida de la parmesana, a quien conocía desde que era niño y a quien le unía una íntima relación de confianza; además, siendo el capellán mayor de las Descalzas Reales es de suponer que medió de algún modo para llevar a feliz término la promesa que la reina tenía pendiente desde 1727. Alentado por la excepcional calidad del Cristo, Aguirre no tardaría en acudir al

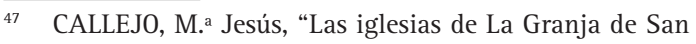
Ildefonso", en Reales Sitios, n. ${ }^{\circ}$ 116, Madrid, 1993, pp. 43-44, y nota 6.

48 LORD, Eileen A., Luis Salvador..., opus cit., pp. 1416, para el Cristo del Perdón; en pág.14 tenemos la transcripción de la estampa, que la autora ya había publicado en 1952: RODRÍGUEZ-MOÑINO, Antonio y LORD, Eileen A., "Juan Antonio Salvador Carmona. Grabador del siglo XVIII (1740-1805)”, en Boletín de la Sociedad Española de Excursiones, Volumen LVI, Madrid, 1952, p. 67. Un ejemplar del grabado en la BNE, INVENT/13716.

49 La profesora García Gaínza abundó en esta idea a partir de los datos que ya había recogido E.A. Lord: LORD, Eileen A., Luis Salvador..., opus cit., pp. 15-16; GAR-

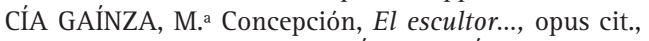
pp. 70-71. Vid., etiam, MARTÍN GONZÁLEZ, Juan J., Luis Salvador Carmona..., opus cit., pp. 73 y 78-79. Sani fue además el pintor encargado en un principio de decorar ambas capillas con dos lienzos que finalmente se retiraron por razones de humedad y falta de pago: CALLEJO, M. a Jesús, Las iglesias de La Granja..., opus cit., pp. 43-44, y nota 6 . taller de Luis Salvador Carmona para encargarle la escultura mariana destinada a Brozas, y cuya iconografía, advocada al socorro que María brinda contra el demonio y en defensa de los cristianos y el cristianismo, estaba en todo punto justificada al ir destinada a un convento perteneciente a la Orden alcantarina ${ }^{50}$.

Los decretos de supresión de 1835, la exclaustración de las freiras y el nuevo uso que se hizo del edificio como sede de las escuelas públicas desde al menos $1844^{51}$, fueron las circunstancias que determinaron el traslado de la escultura mariana del Socorro a la iglesia parroquial de Brozas. A esta larga serie de vicisitudes se sumó la pérdida del grupo de la Asunción que originalmente presidía el retablo mayor de la iglesia, un desafortunado incidente ocurrido a raíz del incendio que sufrió el templo a mediados de la década de 1940 y en sustitución del cual se optó por trasladar, desde el retablo colateral que hasta entonces había ocupado, la escultura del Socorro y si-

50 Para la iconografía, vid., entre otros trabajos, el ya clásico de TRENS, Manuel, María. Iconografía de la Virgen en el Arte Español, Plus Ultra, Madrid, [1947], pp. 331-342.

51 En virtud del oficio remitido el 14 de mayo de 1836 por don Ramón y Montero, obispo de Coria (1830-1847), al secretario de estado del despacho de Gracia y Justicia, sabemos que todos los conventos de la diócesis ya estaban suprimidos para esa fecha, a excepción del que fundara San Pedro de Alcántara en el Palancar (Cáceres) (: REVUELTA GONZÁLEZ, Manuel, La Exclaustración (1833-1840), Fundación Universitaria San Pablo CEU, Madrid, 2010 -2a ed.; la primera es de 1976-, p. 385, nota 79), y del conventual alcantarino de San Benito, que fue designado para casa de venerables de la diócesis (: AHN, Consejos, Leg. 12074, 14 de mayo de 1836; la referencia parte de la obra citada de Revuelta González, si bien hemos consultado el expediente y ampliado el contenido hasta ahora publicado). El convento de San Pedro de Brozas debió ser desamortizado a raíz del R.D. de 25 de julio de 1835 (sobre este decreto: REVUELTA GONZÁLEZ, Manuel, La Exclaustración..., opus cit., pp. 353 y ss.), por el que se suprimieron todas aquellas casas que no tuvieran doce religiosos profesos; en 1791 tenemos constancia que solo había tres religiosas y una novicia en el cenobio brocense: RODRÍGUEZ CANCHO, Manuel y BARRIENTOS ALFAGEME, Gonzalo (eds.), Interrogatorio de la Real Audiencia. Extremadura a finales de los tiempos modernos. Partido de Alcántara, Asamblea de Extremadura, Mérida, 1993, p. 173. En una carta remitida al jefe del Negociado de Propiedades de la provincia de Cáceres el 27 de marzo de 1880, consta que el edificio del antiguo convento de San Pedro se utilizaba desde 1844 para las escuelas públicas: AHPCC, Clero, Leg. 174, Exp. 150. Véase también el trabajo de CARRASCO MONTERO, Gregorio, Desamortización del Real Convento de San Pedro..., opus cit., p. 379. 
tuarla en el camarín del presbiterio, donde se venera desde $1948^{52}$. En la fototeca del CSIC se conserva una imagen del retablo mayor (Fig. 4) tomada a comienzos del siglo pasado; procede del manuscrito original que José Ramón Mélida Alinari (1856-1933) entregó en el Ministerio de Instrucción Pública y Bellas Artes en 1918 con el Catálogo Monumental y Artistico de la provincia de Cáceres (1914-1918), publicado en 1924 sin la fotografía que nos interesa, conservada en el tomo primero de las láminas y autorizada como obra de Mélida gracias al tampón azul y morado que así la identifica ${ }^{53}$. A través de la imagen comprobamos el estado previo del retablo al incendio descrito, y apreciamos con nitidez la escultura a la que sustituyó la obra de Carmona, la cual, además, había sido ejecutada muy pocos años después de haberse concluido la hechura del conjunto arquitectónico lignario que hoy la alberga (Fig. 5). El retablo es obra del citado Bartolomé Jerez, maestro de arquitectura vecino de Trujillo; la autoría la conocíamos desde $1986^{54}$, pero no así la cronología exacta de la obra (octubre/1745-diciembre/1747), el precio en el que se ajustó (en proporción a los 50.000 reales de fianza que otorgó el maestro), el asiento documental del que pro$\operatorname{cede}^{55}$, y tampoco el hecho de haber sido la admiración que causó el conjunto en la villa la que deparó el contrato del mismo maestro

52 CARRASCO MONTERO, Gregorio, Iglesia parroquial de Brozas. "La Catedralina" de Santa María de la Asunción, Edilesa, León, 1994, p. 24, para el dato sobre el incendio; TORRES PÉREZ, José M. ${ }^{\mathrm{a}}$, Bartolomé de Jerez y Luis Salvador..., opus cit., p. 397, donde recoge el traslado de la escultura mariana desde un retablo colateral al mayor.

53 HIDALGO BRINQUIS, M. ${ }^{a}$ del Carmen, “Interpretación material de los Catálogos Monumentales de España", en AA.VV., El Catálogo Monumental de España (19001961). Investigación, restauración y difusión, CSIC, Madrid, 2012, p. 86; el catálogo se realizó entre el 18 de mayo de 1914 y el 1 de julio de 1918; MÉLIDA ALINARI, José Ramón, Catálogo Monumental de España. Provincia de Cáceres, Ministerio de Instrucción Pública y Bellas Artes, Madrid, 1924, 3 vols. La referencia sobre la imagen: CSIC, Archivo del Centro de Ciencias Humanas y Sociales, Junta de Ampliación de Estudios Históricos, Sección Arte y Arqueología, Archivo Manuel Gómez-Moreno y Ricardo Orueta, sign. a ATN/GMO/ c08680; fig. 105 del original manuscrito del Catálogo Monumental de Cáceres (1914-1918).

54 ANDRÉS ORDAX, Salvador (Dir.), Monumentos Artísticos de Extremadura, Editora Regional de Extremadura, Salamanca, 1986, p. 127.

55 AHN, Órdenes Militares, Leg. 6243, s.f., escrituras de 20 de diciembre de 1747. para que ejecutara el tabernáculo del convento de San Pedro, con el que se inició un proceso de ornamentación del templo que, en última instancia, deparó el contrato de la escultura de Ntra. Sra. del Socorro con el taller de Luis Salvador. Los designios de Clio fueron los que hicieron posible que hoy perdure en Brozas el binomio Salvador Carmona y Bartolomé Jerez, lo mismo que en la iglesia parroquial de Serradilla, aunque en este caso la escultura de la Asunción (1749) se contrató para presidir el actual retablo mayor, obra también del maestro trujillano $(1735)^{56}$.

Antonio Milón López y las imagénes para la iglesia de Nuestra Señora del Rosario, en la Granja de San Ildefonso

Las referencias que tenemos acerca de Antonio Milón López (Porto Azurro, Italia, 1679-Aranjuez, 1762) son mucho más parcas que en el caso de Tiburcio de Aguirre; sin embargo, el desempeño de confesor de la reina madre que se recoge en la Gaceta de Madrid de $1762^{57}$, nos permite constatar que también estuvo estrechamente unido al círculo más personal y privado de Isabel de Farnesio. Su vínculo con el entorno real se documenta a partir del mes de julio de 1739 , en el que la reina primera viuda, Mariana de Neoburgo (1667-1740), le nombró su "Capellan de Honor" para servir en el real oratorio del palacio del Duque del Infantado, en Guadalajara, a donde se había retirado ese mismo año, y para que fuera su confesor personal $^{58}$. Este nombramiento hizo posible que Antonio Milón accediera como agregado a la Real Capilla, y que a partir de julio de 1742 se documente en calidad de confesor de la reina

\footnotetext{
56 LORD, Eileen A., "Una obra desconocida de Luis Salvador Carmona”, en Archivo Español de Arte, Volumen XXIV, n. ${ }^{\circ}$ 95, Madrid, 1951, pp. 247-249. Sobre Bartolomé Jerez, vid. MÉNDEZ HERNÁN, Vicente, El retablo en la Diócesis de Plasencia (Siglos XVII-XVIII), Servicio de Publicaciones de la Universidad de Extremadura, Cáceres, 2004, pp. 627-644; el retablo de Serradilla en pp. 629-630.

57 Así se recoge en la Gaceta de Madrid, n. ${ }^{\circ} \quad 24$, $15 / 06 / 1762$, p. 200, donde se daba a conocer su fallecimiento.

58 AGP, Real Capilla, Caja 72, Exp. 10, s.f., 1 y 5 de julio de 1739 (retiro a Guadalajara y nombramiento de capellán de honor); AGP, Personal, Caja 682, Exp. 25, "Expediente personal de Antonio Milón López", s.f., 28 de febrero de 1740, donde consta que fue el confesor personal de la reina primera viuda.
} 


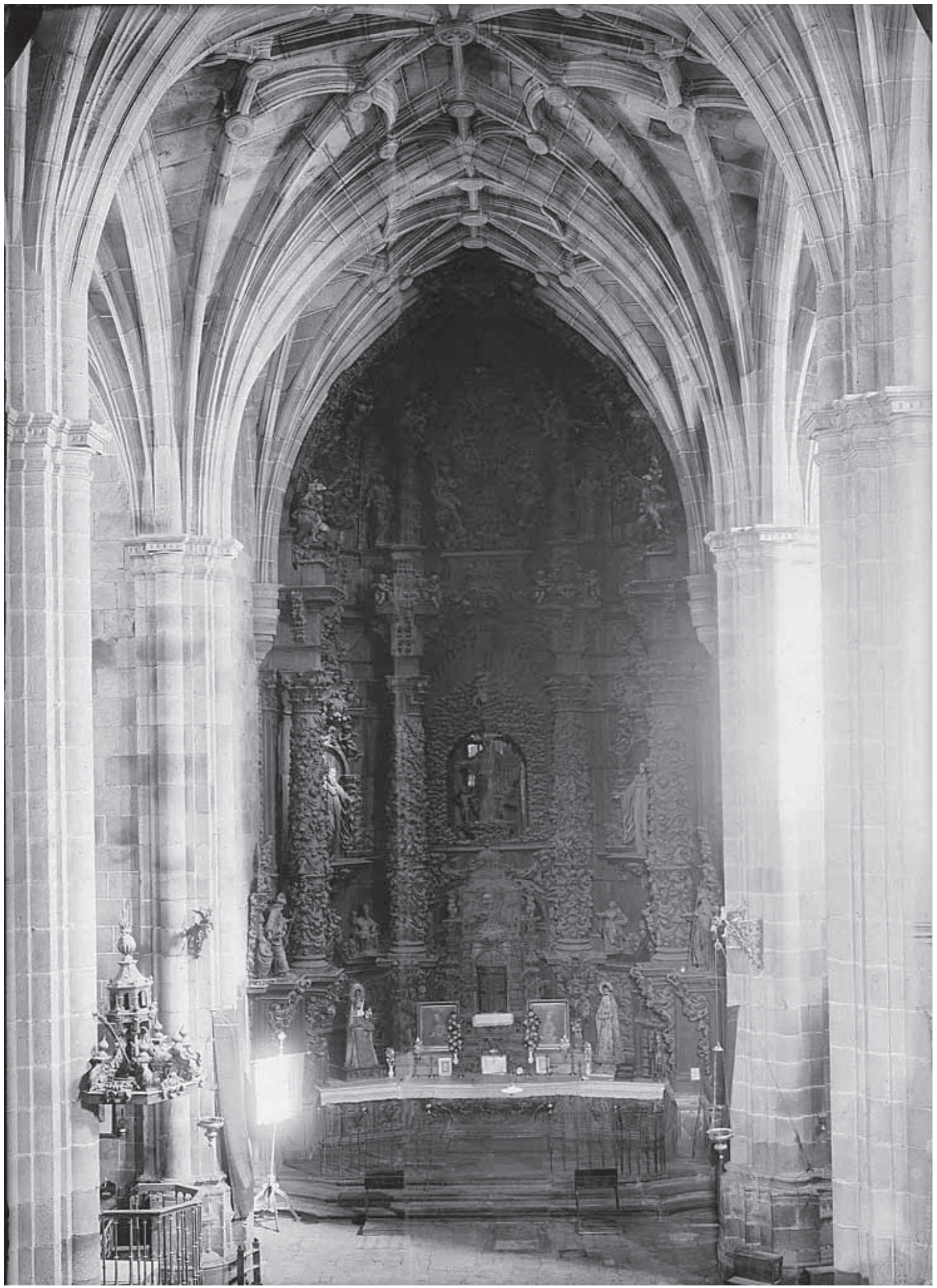

Fig. 4. José Ramón Mélida. Brozas. Iglesia parroquial de la Asunción, interior. 1914-1918. Gelatino-bromuro sobre vidrio, 13 x 18 cm. Madrid, CSIC, Archivo del Centro de Ciencias Humanas y Sociales, sign. ${ }^{a}$ ATN/GMO/c08680. 


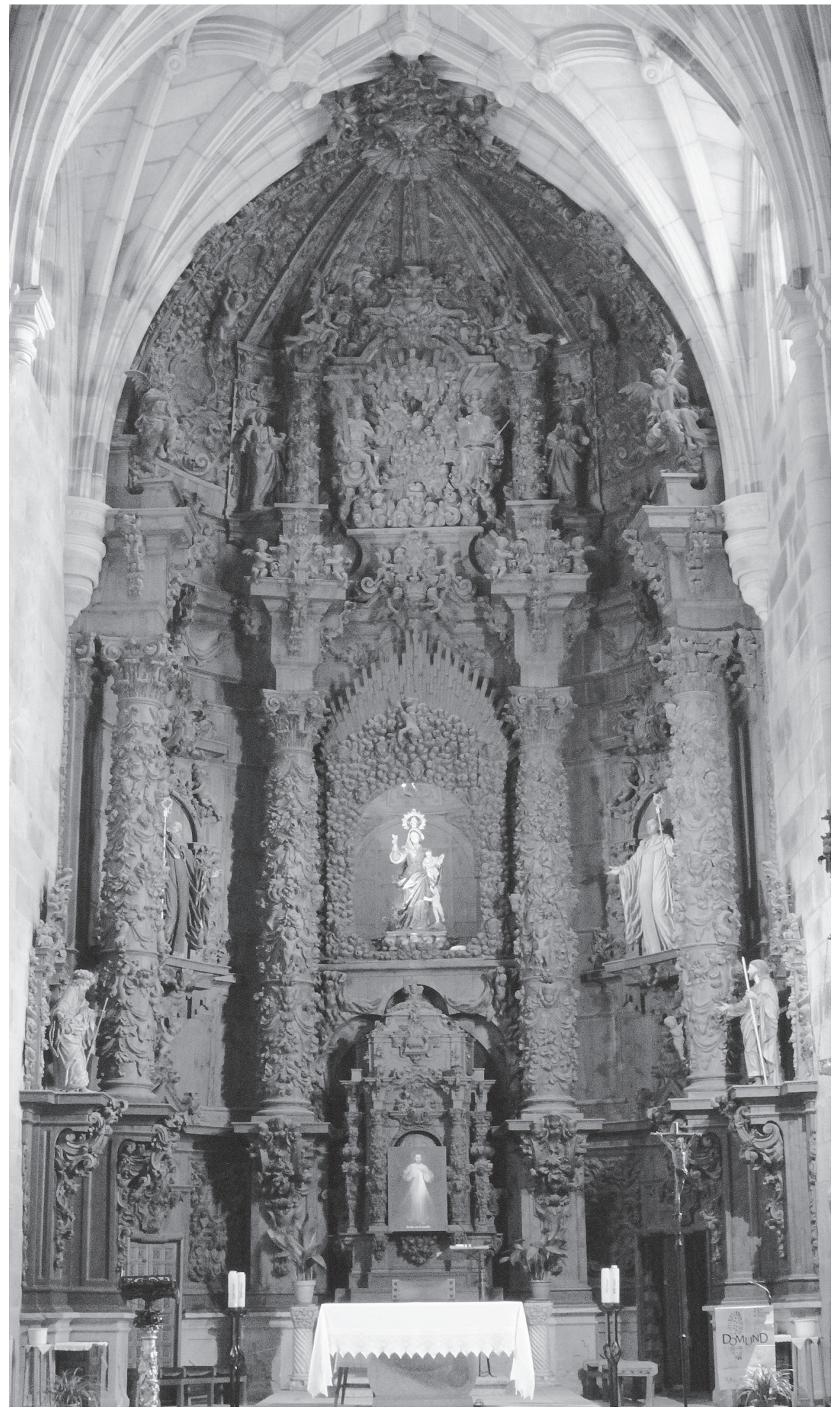

Fig. 5. Bartolomé Jerez. Retablo mayor. Brozas, iglesia de Nuestra Señora de la Asunción, 1745-1747. Foto del autor. 
parmesana y como abad de la Real Colegiata de la Santísima Trinidad, en el Real Sitio de San Ildefonso, priorato para el que fue designado ese mismo año $(1742)^{59}$. Su ascenso en la corte también lo comprobamos a través del cargo que ocupaba como miembro del consejo del rey ${ }^{60}$, y por el hecho de haber sido consagrado con el título de arzobispo de Edesa en la iglesia de San Jerónimo el Real el 5 de abril de 1745, dignidad que ocupó de forma honorífica al estar situada la archidiócesis en Mesopotamia $^{61}$. Pocas más referencias tenemos sobre la trayectoria de Milón López, salvo algunos datos referentes al desempeño de su actividad ministerial, conservados en El Escorial (1754 y 1755) y en el Archivo de Protocolos de Madrid (1752); o relativos a su vida personal (1749 y 1760) ${ }^{62}$.

Fue en ese último año de 1760, el día 24 de enero, cuando otorgó testamento ante el escribano madrileño Mateo Álvarez de la Fuente $^{63}$, donde consta que fue hijo del matrimonio formado entre los entonces ya difuntos Andrés Milón, capitán del puerto y plaza de Porto Longone, y María López; y que fue en esa localidad italiana de la isla de Elba, en el archipiélago

59 AGP, Real Capilla, Caja 72, Exp. 10, s.f., 13 de julio de 1739 (agregado a la Real Capilla); AGP, Personal, Caja 682, Exp. 25, "Expediente personal de Antonio Milón López", s.f., julio de 1742 (no figura el día), donde consta su nombramiento como Abad en virtud de la cédula firmada en el palacio del Buen Retiro, y también su cargo de confesor de la reina. Vid., etiam, en relación con el citado abadiato, AGP, Real Capilla, Caja 192, Exp. 5, 1744-1746, s.f.

60 Gaceta de Madrid, n. ${ }^{\circ}$ 24, 15/06/1762, p. 200.

${ }_{61}$ FLÓREZ DE SETIÉN Y HUIDOBRO, Enrique, OSA; FORT, Carlos Ramón; y FUENTE, Vicente de la, España sagrada, continuada por la Real Academia de la Historia, Impr. de José Rodríguez, Madrid, 1879, t.LI, Tratado LXXXIX: de los obispos españoles titulares de iglesias in partibus infidelium, ó auxiliares en las de España, p. 128, para el nombramiento, cuya fecha tomo de $<$ https://en.wikipedia.org/wiki/Bishopric_of_Edessa> [consulta: 08/XI/2016]. Vid., etiam, FLÓREZ DE SETIÉN Y HUIDOBRO, Enrique, OSA, España Sagrada. Teatro Geográfico-Histórico de la Iglesia de España, Impr. de José Rodríguez, Madrid, 1879 (3a Ed.), t.I, p. 161, donde consta la ubicación de la diócesis, en Mesopotamia, razón por la que era un cargo honorífico.

62 Real Biblioteca del Monasterio de San Lorenzo de El Escorial, Caja XLV, Exp. 27; GONZÁLEZ PALENCIA, Ángela, Colección de Documentos..., opus cit., pp. 60 (sobre su actividad ministerial), 23 y 151 (sobre su vida personal).

63 La referencia documental la recoge GONZÁLEZ PALENCIA, Ángela, Colección de Documentos..., opus cit., p. 151. Para el contenido que resumimos a continuación vid. Archivo Histórico de Protocolos de Madrid (en adelante, AHPM), escribano Mateo Álvarez de la Fuente, Leg. 17622, fols. 57r-60r.
Toscano y hoy denominada Porto Azurro, donde nuestro personaje había nacido en 1679. Antonio Milón dispuso que su entierro se hiciera con "la maior humildad[,] sin embargo si su Magestad la Reyna Madre mi Ama y Señora por su alta piedad y charidad se dignare mandar se ejecute el funeral y entierro como a confesor suio y su mas humilde capellan[,] en este caso quiero que se disponga y haga conforme sea mas de el Real agrado de Su Magestad (...)". El vínculo que le unía a la reina fue también determinante para que dispusiera ser enterrado en la iglesia del Rosario si fallecía en el Real Sitio de San Ildefonso, aunque finalmente el óbito sucedió en Aranjuez y fue inhumado en la iglesia madrileña de San Pedro el Real ${ }^{64}$, según él mismo había dispuesto en caso de morir en otro lugar que no fuera aquel Real Sitio. Su vida al servicio de la Corona hizo posible que nombrara entre sus albaceas y testamentarios a distintos miembros de la corte, entre ellos su capellán Diego Rodríguez Hermoso, racionero en la Real Colegiata de San Ildefonso y secretario del marqués de Gamoneda, quien, a su vez, lo era de la parmesana; a Diego Ramos de Velasco, "contador de la casa de la Reyna Madre"; y a sus sobrinos y herederos Juan Pablo Mateos, secretario asimismo de su majestad y "oficial de la Secretaría de Nueba España”, y a su esposa María Pinto de Acevedo.

Desde su abadiato en la Colegiata de La Granja, Antonio Milón fue testigo de las empresas artísticas que los reyes de España emprendían para engalanar los Reales Sitios. El hecho de haber sido confesor de Isabel de Farnesio desde -al menos- 1742 hasta $1760^{65}$, nos permite pensar sin ninguna reserva que siguió muy de cerca el interés que la reina puso en la construcción y ornato de la iglesia de Nuestra Señora del Rosario, en Sal Ildefonso, que el propio Milón bendijo en $1752^{66} \mathrm{y}$ a cuya ornamentación contribuyó con las esculturas de Ntra. Sra. del Pilar y San Francisco Javier, que le encargaría a Luis Salvador Carmona tras el impacto que debió causarle la efigie del Cristo del Perdón (1751). Antonio Milón -o

${ }_{64}$ FERNÁNDEZ GARCÍA, Matías, Parroquias madrileñas de San Martin y San Pedro el Real. Algunos personajes de su archivo, Caparrós Editores, Madrid, 2004, p. 448.

${ }^{65}$ LAVALLE-COBO, Teresa, Isabel de Farnesio..., opus cit., p. 214.

66 MARTÍN SEDEÑO, Santos, Descripción del Real Sitio de San Ildefonso, sus jardines y fuentes, Impr. de Eduardo Baeza, Segovia, 1849, p. 29. 
Miloni como también figura en las fuentes- se había convertido en un hombre muy cercano para la reina, y esa plena confianza justifica incluso que llegara a asistir al propio Felipe $\mathrm{V}$ en su lecho de muerte, al que apretó su mano y absolvió en los minutos previos a su fallecimiento $^{67}$.

La historiografía de las tallas que costeó Antonio Milón es singular y hasta llamativa. Eileen A. Lord las dio a conocer en 1953 y las atribuyó a la gubia del artista, mientras que ese mismo año González Palencia publicaba su Colección de Documentos sobre Madrid y la carta de pago que el escultor otorgó por ambas piezas ${ }^{68}$. Sin embargo, y a pesar del tiempo transcurrido, la crítica histórico-artística nunca ha puesto en relación ambas publicaciones, en las que tampoco se hacía mención, respectivamente, ni a la documentación ni tampoco a la existencia de las obras.

Según la carta de pago que el artista rubricó en Madrid el 23 de junio de 1758, ambas esculturas le habían sido encargadas por orden de don José Sánchez Aula, "prebendado de la Insigne y Real Colegiata", a través de Juan Bartolomé, vecino de San Ildefonso ${ }^{69}$. Se trataba de "dos imágenes, la una de Ntra. Sra. del Pilar y la otra de San Francisco Xavier, que se colocaron en la parroquial del mismo sitio", a cuya cuenta el otorgante ya tenía recibidos 3.000 reales de vellón; “y aunque estaba (...) en que las había ajustado en mayor cantidad, habiéndose ofrecido varios debates y dudas, y mediado personas a quienes ha deseado complacer, se ha convenido y ajustado en la cantidad de seis mil reales de vellón". Los 3.000 reales que restaban para completar el pago le fueron entregados "de orden del Ilmo. señor
Don Antonio Milón López, arzobispo de Edesa, abad de dicha Real e Insigne Collegiata y confesor de la Reina viuda nuestra señora"7o, a través de Domingo Antonio Gorriti, también vecino de San Ildefonso y hombre de confianza para nuestro personaje según se desprende de su testamento ${ }^{71}$. Eileen Lord propuso para ambas tallas una cronología situada entre 1745 y $1750^{72}$, que sugerimos posponer al menos hasta $1751 / 52$ por las referencias aducidas, y también teniendo en cuenta el retraso en la liquidación del pago por ambas esculturas.

Y un último apunte. Como ha señalado la crítica histórico-artística en varias ocasiones, el San Francisco Javier de La Granja es prácticamente una réplica del que hizo Luis Salvador para la Real Congregación de San Fermín de los Navarros en 1746, escultura que fue destruida en el transcurso de la última contienda nacional y hoy es conocida a través de la fotografía del archivo Moreno $^{73}$. Como argumentó Sagüés Azcona, esta obra fue, muy probablemente, una donación de don Francisco de Indaburu y Borda, quien había ingresado en la Congregación en julio de 1736, y era a la sazón tesorero de Isabel de Farnesio desde octubre de 1748, un desempeño para el que Carlos III le ratificó en $1759^{74}$. Si tenemos en cuenta el vínculo que la reina tenía con la citada iglesia del Rosario y con Antonio Milón, es posible establecer la conexión entre ambas tallas y justificar así el modelo que Luis Salvador Carmona utilizó para realizar el San Francisco Javier destinado al Real Sitio de San Ildefonso; una elección en la que debió mediar de algún modo el tesorero de la parmesana, aunque sin duda el nexo de unión entre ambas esculturas fue la propia Isabel de Farnesio.

67 Así consta en el manuscrito titulado Epitome de la vida y costumbres [,] muerte y entierro de el Catholico Monarca D. Phelipe Quinto, BNE, Mss/10.818/30, fol. 7r. Citado por PÉREZ SAMPER, M. a Ángeles, Isabel de Farnesio, Plaza y Janés, Barcelona, p. 408, nota 566. La referencia a la foliación del manuscrito es nuestra.

68 LORD, Eileen A., Luis Salvador..., opus cit., pp. 24-25 y 27; GONZÁLEZ PALENCIA, Ángela, Colección de Documentos..., opus cit., pp. 573-575, donde se incluye la transcripción de la escritura otorgada ante el escribano madrileño Mateo Álvarez de la Fuente, Leg. 17620, fol. 255r y ss.

69 Juan Bartolomé también figura en la correspondencia entre Luis Salvador Carmona y las hermandades de la iglesia del Rosario, en La Granja. La transcripción íntegra de las cartas en MARTÍN GONZÁLEZ, Juan J., Luis Salvador Carmona..., opus cit., pp. 96-100.

70 GONZÁlEZ PALENCIA, Ángela, Colección de Documentos..., opus cit., p. 574.

${ }^{71}$ Antonio Milón también le nombró entre sus albaceas y testamentarios, y afirmaba tener depositado en su poder "alguna cantidad y de que tengo papeles de resguardo": AHPM, escribano Mateo Álvarez de la Fuente, Leg. 17622, fol. 59v.

72 LORD, Eileen A., Luis Salvador..., opus cit., pp. 24-25.

73 Fototeca del Instituto del Patrimonio Cultural de España, Archivo Moreno, n. ${ }^{\circ}$ de inventario 35831-B.

74 SAGÜÉS AZCONA, Pío, OFM, La Real Congregación..., opus cit., pp. 168 y 180 (y nota 38). Las fechas en las que desempeñó el cargo de tesorero de la parmesana las tomo de CASTELLANO DE GASTÓN, Gaspar, "Mujeres baztanesas en la corte (siglo XVIII)", en Principe de Viana, Volumen 254, Pamplona, 2011, p. 304. 